\title{
High frequency oscillatory ventilation in infants with increased intra-abdominal pressure
}

\author{
Tai Fai Fok, Pak Cheung Ng, William Wong, Cheuk Hon Lee, King Woon So
}

\begin{abstract}
Aims-To describe the short term effect of high frequency oscillatory ventilation on infants with severe abdominal distension who could not be conventionally ventilated.

Methods-Eight infants $(25$ to 38 gestational weeks, birthweight 600-3200 g, postnatal age 1 to 190 days) with a variety of intra-abdominal pathologies, resulting in severe abdominal distension and failure of conventional ventilation, were studied. Results-The oxygenation status of all infants significantly improved within an hour of changing from conventional to high frequency oscillatory ventilation. Infants who were hypercapneic on conventional ventilation also showed a reduction in $\mathrm{PaCO}_{2}$. As a group, the mean (SD) $\mathrm{PaO}_{2} / \mathrm{FIO}_{2}$ improved from $4.99(0.98) \mathrm{kpa}$ to $11.55(3.8) \mathrm{kpa}(P=0.002)$, and the $\mathrm{PaCO}_{2}$ from 6.48 (2.12) kpa to 4.89 (1.22) kpa $(\mathbf{P}=0.028)$. These improvements were sustained throughout the next $\mathbf{4 8}$ hours.

Conclusion-High frequency oscillatory ventilation seems to be an effective rescue measure for infants with respiratory failure secondary to increased intraabdominal pressure.

(Arch Dis Child 1997;76:F123-F125)
\end{abstract}

Keywords: abdominal distension; high frequency oscillatory ventilation; respiratory failure.

Infants with severe abdominal distension often have reduced lung volume and impaired diaphragmatic movement. In extreme cases conventional mechanical ventilation may be unable to maintain satisfactory oxygenation or ventilation, resulting in respiratory failure. This is often the immediate cause of death in infants with severe intra-abdominal pathologies, such as necrotising enterocolitis. High frequency oscillatory ventilation is effective in allowing collapsed alveoli to function and maintaining lung volume, but its role in the management of infants with increased intra-abdominal pressure has not been determined. We describe eight infants with severe abdominal distension who failed conventional mechanical ventilation but were successfully ventilated with high frequency oscillatory ventilation.

\section{Case reports}

From June 1994 to February 1996, eight preterm infants with a variety of intraabdominal complications were treated with high frequency oscillatory ventilation (SensorMedics 3100A, SensorMedics Inc., Yorba Linda, California, USA) when conventional mechanical ventilation (Infant Star neonatal ventilator, Infrasonics Inc., San Diego, USA) failed to provide satisfactory oxygenation and/or ventilation. Their details and clinical course are summarised in table 1.

Immediately before the start of highfrequency oscillatory ventilation, the ventilator settings of these infants were: peak inspiratory pressure (PIP) $30-42 \mathrm{~cm} \mathrm{H}_{2} \mathrm{O}$; positive endexpiratory pressure (PEEP) $4-6 \mathrm{~cm} \mathrm{H}_{2} \mathrm{O}$, rate 30-60 breaths per minute; inspiratory time 0.4-0.8 seconds; and $\mathrm{FIO}_{2}$ 1.0. These settings achieved optimal blood gases after multiple adjustments of the ventilator parameters, including increasing the PIP, PEEP, and inspiratory time. High frequency oscillatory ventilation was started at the following settings: frequency $10 \mathrm{~Hz}$ (600 breaths per minute); fractional inspiratory time 0.33 (inspiratory:expiratory ratio of $1: 2) ; \mathrm{FIO}_{2} 1.0$; mean airway pressure 1-2 $\mathrm{cm} \mathrm{H}_{2} \mathrm{O}$ higher than the mean airway pressure on conventional ventilation; and pressure amplitude sufficient to produce visible chest vibration. Subsequently, mean airway pressure and $\mathrm{FIO}_{2}$ were adjusted to maintain an arterial oxygen tension of 8-12 kpa. Priority was given to reducing mean airway pressure once $\mathrm{FIO}_{2}$ was decreased to 0.4 .

The outcome of the infants is summarised in table 1 . The oxygenation status of all infants significantly improved, expressed as an oxygenation efficiency index $\left[\mathrm{PaO}_{2}(\mathrm{kpa}) / \mathrm{FiO}_{2}\right]$, almost immediatley after the start of high frequency oscillatory ventilation (fig 1). A decline in $\mathrm{PaCO}_{2}$ was also observed in infants who were hypercapneic (cases 2, 3, and 5) during conventional ventilation (fig 1). As a group, the differences in $\mathrm{PaO}_{2} / \mathrm{FIO}_{2}$ and $\mathrm{PaCO}_{2}$ before and one hour after high frequency oscillatory ventilation were significant (mean SD): $\mathrm{PaO}_{2} /$ $\mathrm{FIO}_{2} 4.99$ (0.98) kpa vs 11.55 (3.8) kpa, $\mathrm{P}=$ $0.002 ; \mathrm{PaCO}_{2} 6.48$ (2.12) kpa vs 4.89 (1.22) kpa, $\mathrm{P}=0.028$; paired $t$ test). These improvements were sustained throughout the next 48 hours (fig 2).

Once stabilised on high frequency oscillatory ventilation, mean airway pressure could be gradually decreased in all infants, and none had radiological or clinical evidence of hyperinflation of the lungs. However, all infants required multiple boluses of plasma expander to maintain satisfactory blood pressure, peripheral perfusion, and urine output. Three infants had either grade II or III intraventricular haemorrhage before high frequency oscillatory 
Table 1 Demographic characteristics and clinical course of infants studied

\begin{tabular}{|c|c|c|c|c|}
\hline Case No & $\begin{array}{l}\text { Gestational age (weeks) } \\
\text { Birthweight }(g)\end{array}$ & Abdominal condition & $\begin{array}{l}\text { Age when } \\
\text { HFOV started }\end{array}$ & Outcome \\
\hline 1 & Female, 30, 1190 & $\begin{array}{l}\text { NEC with gangrenous bowel and multiple } \\
\text { perforations; Enterobacter septicaemia and DIC }\end{array}$ & Day 14 & Extubated on day 30 \\
\hline 2 & Male, 25, 600 & $\begin{array}{l}\text { NEC with gangrenous bowel and multiple } \\
\text { perforations }\end{array}$ & Day 17 & $\begin{array}{l}\text { Initial improvement; died on day } 22 \text { from } \\
\text { uncontrolled sepsis, renal failure and DIC }\end{array}$ \\
\hline 3 & Male, 25,850 & $\begin{array}{l}\text { NEC with perforation; Acinectobacter septicaemia } \\
\text { and peritonitis }\end{array}$ & Day 63 & Extubated on day 90 \\
\hline 4 & Female, 32, 1150 & $\begin{array}{l}\text { Post-NEC ileal stricture resulting in acute bowel } \\
\text { obstruction and gangrene; Serratia septicaemia }\end{array}$ & Day 50 & Extubated 4 days later \\
\hline 5 & Male, 27, 1155 & $\begin{array}{l}\text { Enterobacter septicaemia meningitis, and peritonitis; } \\
\text { normal intestinal tract }\end{array}$ & Day 57 & Extubated 9 days later \\
\hline 6 & Male, 25,890 & $\begin{array}{l}\text { Massive hepatomegaly, ascites and liver failure } \\
\text { secondary to prolonged TPN }\end{array}$ & Day 190 & $\begin{array}{l}\text { Initial improvement; died on day } 230 \text { from } \\
\text { progressive liver failure }\end{array}$ \\
\hline 7 & Male, 34, 2275 & $\begin{array}{l}\text { Gastroschisis with primary closure, complicated by } \\
\text { Enterobacter septicaemia, peritonitis and DIC }\end{array}$ & Day 4 & $\begin{array}{l}\text { Initial improvement; died on day } 9 \text { from sepsis and } \\
\text { acute renal failure }\end{array}$ \\
\hline 8 & Male, 38, 3200 & $\begin{array}{l}\text { Malrotation of small gut; necrosis and perforation of } \\
\text { stomach; partial gastrectomy }\end{array}$ & Day 1 & Extubated on day 17 \\
\hline
\end{tabular}

HFOV high frequency oscillatory ventilation; NEC necrotising enterocolitis; DIC disseminated intravascular coagulation; TPN total parenteral nutrition.

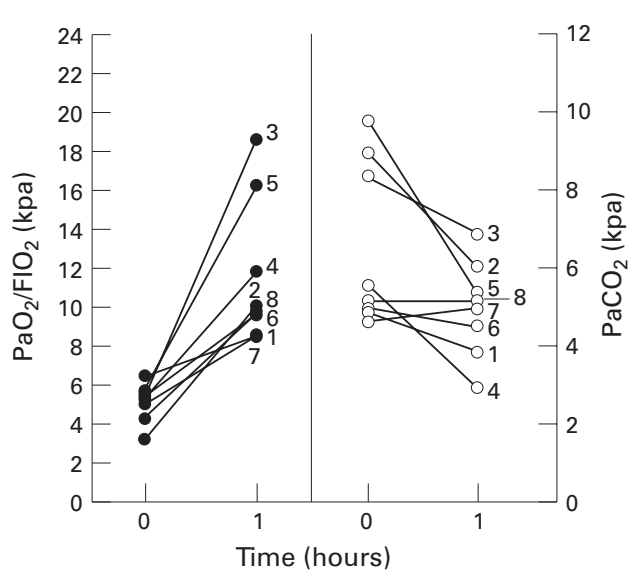

Figure 1 Changes in oxygenation efficiency index $\left(\mathrm{PaO}_{2} /\right.$ $\left.\mathrm{FIO}_{2} ; \bullet\right)$ and $\mathrm{PaCO}_{2}(\mathrm{O})$ one hour after the start of high frequency oscillatory ventilation.

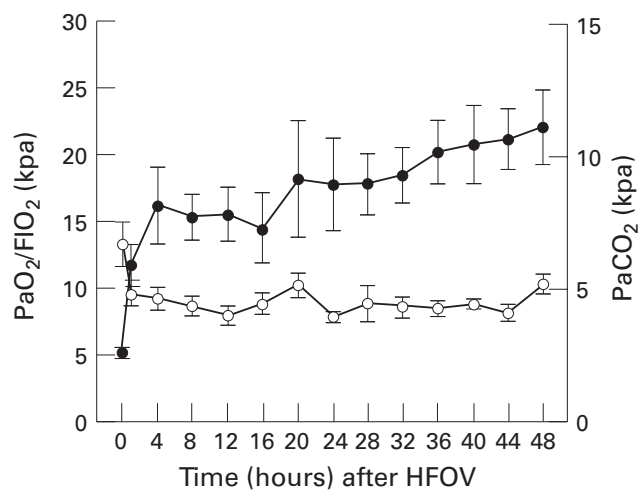

Figure 2 Group means (SEM) of oxygenation efficiency index $\left(\mathrm{PaO}_{2} / \mathrm{FIO}_{2} ; \bullet\right)$ and $\mathrm{PaCO}_{2}(\mathrm{O})$ immediately before (zero hours) and 48 hours after the start of high frequency oscillatory ventilation. Both parameters were significantly higher than those at zero hours (one way repeated measures: ANOVA oxygenation efficiency index $P<0.0001$; $\mathrm{PaCO}_{2} \mathrm{P}=0.0162$; pairwise multiple comparison using the Student-Newman-Keuls method $P<0.05$ for both parameters).

ventilation. Subsequent weekly cranial ultrasound scans showed no extension of their old haemorrhage, and none of the other infants developed intraventricular haemorrhage after starting high frequency oscillatory ventilation. Three infants died, two from uncontrolled infection (cases 2 and 6) and one from progressive liver failure (case 7 ). This last infant was suspected to have had hepatic damage secondary to prolonged total parenteral nutrition, and necropsy confirmed the presence of massive liver necrosis.

\section{Discussion}

Increased intra-abdominal pressure compromises diaphragmatic movement and lung expansion, resulting in restrictive pulmonary insufficiency with reduced lung volumes and compliance. In severe cases conventional mechanical ventilation often fails to achieve adequate lung expansion and ventilation even at high inspiratory pressure. Loss of lung volume is especially severe during expiration when intra-alveolar pressure is decreased. This results in reduced functional residual capacity, ventilation/perfusion mismatch, and hypoxia. Hypercapnia ensues when abdominal distension becomes severe enough to impair alveolar expansion during inspiration, resulting in alveolar hypoventilation. The use of a high positive end-expiratory pressure may reduce alveolar collapse during expiration, but may cause further reduction in tidal volume with an increase in $\mathrm{PaCO}_{2}{ }^{1}$ A positive end-expiratory pressure of $7 \mathrm{~cm} \mathrm{H} \mathrm{H}_{2} \mathrm{O}$ had been tried in four of the infants but had resulted in further deterioration of hypercapnia without improvement in oxygenation.

High frequency oscillatory ventilation is an efficient mode of ventilation for infants with a variety of lung conditions, including respiratory distress syndrome, ${ }^{2-6}$ meconium aspiration syndrome, ${ }^{2}$ lung hypoplasia, ${ }^{2}$ pulmonary air leaks, ${ }^{27}$ persistent pulmonary hypertension and congenital diaphragmatic hernia. ${ }^{89}$ As far as we know, its use in infants with respiratory failure secondary to increased intra-abdominal pressure has not been described. There is a sound theoretical basis for the use of high frequency oscillatory ventilation in this group of infants. Unlike conventional ventilation, it provides a near-constant positive airway pressure that keeps the alveoli open without the loss of end-expiratory volume. This unique mechanism effectively minimises ventilation/ perfusion mismatch and improves oxygenation. Carbon dioxide removal is achieved by active exhalation generated by the oscillator and does not seem to be affected by the high resting lung volume. Data from animal studies suggest that 
when compared with conventional ventilation, high frequency oscillatory ventilation is associated with more uniform gas distribution within the lungs and less regional hyperinflation or alveolar collapse. ${ }^{1011}$ This, together with the lack of bulk gas movement and substantial reduction in phasic pressure and volume changes in the distal airway, decrease the risk of pulmonary air leaks and chronic lung injury. ${ }^{67}$ This potential advantage is particularly relevant to infants requiring high pressure ventilation.

While the therapeutic superiority of high frequency oscillatory ventilation over conventional ventilation should ideally be verified with a randomised controlled trial, our observations provide preliminary evidence that high frequency oscillatory ventilation is beneficial to infants with severe abdominal distension. All infants were significantly hypoxic despite treatment with conventional ventilation using various ventilation strategies. Rescue treatment with high frequency oscillatory ventilation was followed by rapid and sustained improvement in oxygenation. Arterial carbon dioxide tension became normal in those infants with preexisting hypercapnia. All these changes were too extensive and too rapid to be accounted for by spontaneous improvement of the patients.

None of the infants developed lung hyperinflation, a known complication of high frequency oscillatory ventilation: this may impede venous return, resulting in impaired cardiac output and intraventricular haemorrhage. ${ }^{12} \mathrm{We}$ speculate that the restrictive force imposed by the high intra-abdominal pressure makes lung hyperinflation less likely in these infants than in those with non-restrictive lung diseases, such as hyaline membrane disease and meconium aspiration syndrome. All infants, however, required multiple boluses of volume expander within the first 48 hours of high frequency oscillatory ventilation. This suggested that even in the absence of radiological or clinical evidence of lung hyperinflation, the constantly increased intrathoraxic pressure during high frequency oscillatory ventilation may still compromise cardiac output, resulting in hypotension and decreased tissue perfusion and urine output. Close monitoring of circulatory state and prompt correction of any volume deficit are mandatory, especially in this category of infants who are at risk of severe hypovolaemia due to continuous loss of fluid into the peritoneal cavity.

Three of the infants died, but none from respiratory failure. All three deaths occurred after the infants had shown sustained improvement in their respiratory status. The high mortality merely reflected the severity of their underlying pathologies or intercurrent illnesses. Our experience shows that high frequency oscillatory ventilation provides effective ventilation and rapid improvement in oxygenation in infants with increased intra-abdominal pressure who could not be effectively ventilated with conventional ventilation.

1 Bartholomew KM, Brownlee KG, Snowden S, Dear PRF. Bartholomew KM, Brownlee KG, Snowden S, Dear PRF. 12 .

2 Clark RH, Yoder BA, Sell MS. Prospective, randomized comparison of high-frequency oscillation and conventional ventilation in candidates for extracorporeal membrane oxygenation. $\mathcal{F}$ Pediatr 1994;148:447-54

3 de Lemos RA, Coalson JJ, de Lemos JA, King RJ, Clark RH, Gerstmann DR. Rescue ventilation with high-frequency oscillation in premature baboons with hyaline membrane disease. Pediatr Pulmonol 1992;12:29-36.

4 The HIFO Study Group. Randomized study of highfrequency oscillatory ventilation in infants with severe respiratory distress syndrome. F Pediatr 1993;122:609-19.

5 The HIFI study group. Randomized study of highfrequency oscillatory ventilation in infants with severe respiratory distress syndrome. $\mathcal{F}$ Pediatr 1993;122:609-19.

6 Clark RH, Gerstmann DR, Null Jr. DM, de Lemos RA. Prospective randomized comparison of high-frequency oscillatory and conventional ventilation in respiratory distress syndrome. Pediatrics 1992;89:5-12.

7 Clark RH, Gerstmann DR, Null, Jr. DM, Yoder BA, Cornish JD, Glasier CM, et al. Pulmonary interstitial emphysema treated by high-frequency oscillatory ventilation. Crit Care Med 1986;14:926-30.

8 Varnholt V, Lasch P, Suske G, Kachel W, Brands W. High-frequency oscillatory ventilation and extracorporeal membrane oxygenation in severe persistent pulmonary hypertension of the newborn. Eur F Pediatr 1992;151:76974

9 Miguet D, Claris O, Lapillonne A, Baker A, Chappuis JP, Salle BL. Preoperative stabilization using high-frequency oscillatory ventilation in the management of congenital oscillatory ventilation in the management of congenital diaphragmatic

10 de Lemos RA, Coalson JJ, Gerstmann DR, Null Jr. DM, Ackerman NB, Escobedo MB, et al. Ventilatory management of infant baboons with hyaline membrane disease: the use of high-frequency ventilation. Pediatr Res 1987;21:594-602.

11 de Lemos RA, Coalson JJ, deLemos JA, Gerstmann DR, King RJ, Clark RA, et al. High-frequency oscillatory ventilation improves the non-uniform lung inflation of hyaline membrane disease. Am Rev Respir Dis 1989;139:A438.

12 HIFI Study Group. High-frequency oscillatory ventilation compared with conventional mechanical ventilation in the management of respiratory failure in preterm infants. $N$ Engl Э Med 1989;320:88-93. 